\title{
Debonding/crack initiation and flexural strengths of bilayered zirconia core and veneering ceramic composites
}

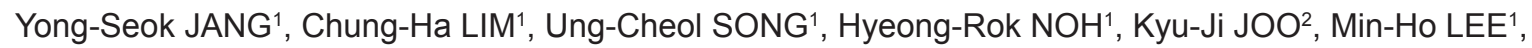 \\ Seung-Geun $\mathrm{AHN}^{3,4}$ and Tae-Sung BAE ${ }^{1,3}$ \\ ${ }^{1}$ Department of Dental Biomaterials, Institute of Biodegradable Materials, BK21 plus Program, School of Dentistry, Chonbuk National University, \\ Jeonju, South Korea \\ ${ }^{2}$ Department of Dental Technology, Gwangju Health College, Gwangju, South Korea \\ ${ }^{3}$ Research Institute of Clinical Medicine of Chonbuk National University, Biomedical Research Institute of Chonbuk National University Hospital, \\ Jeonju, South Korea \\ ${ }^{4}$ Department of Prosthodontics, School of Dentistry, Chonbuk National University, Jeonju, South Korea \\ Corresponding authors, Seung-Geun AHN; E-mail: sgahn@chonbuk.ac.kr, Tae-Sung BAE; E-mail: bts@jbnu.ac.kr
}

\begin{abstract}
The aim of this study was to evaluate the effects of the kinds of veneering ceramics and veneering methods on the debonding/crack initiation and 3-point flexural strengths in bilayered zirconia core and veneering ceramic composites. Zirconia block was used as core material, and Cerabien ZR and Lava Ceram for the layering technique and IPS e.max ZirPress and Amber LiSi-POZ for the heat pressing technique were used as veneering materials. Both debonding/crack initiation and 3-point flexural strengths of bilayered zirconia core and veneering ceramic composites as well as the bi-axial flexural strengths of veneering materials, were higher when using heat pressing technique than layering technique. It was identified that not only bonding strength between zirconia core and veneering materials but also the intrinsic strength of veneering ceramic should be high to prevent chipping of veneering material.
\end{abstract}

Keywords: All-ceramic restorations, Bilayered zirconia core and veneering ceramic composites, Bi-axial flexural strength, Debonding/ crack initiation strength, 3-point flexural strength

\section{INTRODUCTION}

The use of all-ceramic restorations with superior esthetics and functionality is recently increasing for prosthetic treatment. Ceramic is an excellent crown molding material because of its high compressive strength as well as outstanding wear resistance and esthetics. However, ceramic can be easily fractured by stress concentration at defects since it has brittleness ${ }^{1}$. Metal-ceramic restorations reinforced with metal in the substructure have been widely used to solve the problems related to fracture of ceramics with low strength and high brittleness. However, these restorations have been proved to have several disadvantages, such as the increase in brightness caused by light reflection on the opaque porcelain layer, manifestation of shadows of $2-3 \mathrm{~mm}$ in the gums due to light blocking caused by metal coping, exposure of marginal metals, bind failure between metal and porcelain, metal-related allergies, etc. ${ }^{2,3)}$. Thus, the use of all-ceramic restorations with superior esthetics has been increasing.

Zirconia, which has excellent mechanical properties, has been introduced recently as all-ceramic restorative material. Furthermore, as the process of manufacturing restoration has become simpler and more accurate due to the introduction of computer-aided design (CAD)/ computer-aided manufacturing (CAM) technologies, the use of zirconia ceramic when manufacturing

Color figures can be viewed in the online issue, which is available at J-STAGE.

Received Sep 27, 2018: Accepted Mar 11, 2019

doi:10.4012/dmj.2018-321 JOI JST.JSTAGE/dmj/2018-321 restoration has increased ${ }^{4,5)}$. Tetragonal zirconia polycrystalline ceramics (3Y-TZP) stabilized by adding $3 \mathrm{~mol} \%$ of yttria are mainly used for the zirconia block for CAD/CAM processing when manufacturing dental prosthetic appliances ${ }^{6}$. The 3Y-TZP zirconia block remains metastable at room temperature, but changes from tetragonal to monoclinic when applied stress by polishing or blasting treatment. Since a $3-5 \%$ volume expansion takes place during this process, a residual compressive stress layer is created on the surface, which results in improvement in fracture resistance of $3 \mathrm{Y}$ TZP zirconia ${ }^{6-8)}$. Due to these reasons, 3Y-TZP displays excellent strength and fracture toughness at room temperature.

Bilayered zirconia restoration for an incisor, which porcelain is veneered on the lower zirconia core, is widely applied since single structural zirconia restoration has low esthetics. Although such dual structures are esthetic, fracture can occur easily due to the low tensile strength and bonding force of veneering ceramics, and also cracks leading to restoration failure can initiate on the surface of veneered materials or in the bonding interface with the core ${ }^{9,10}$. It has been reported that the veneering ceramics has higher strength when using heat pressing technique than when using layering technique ${ }^{11)}$.

In this study, veneering ceramics were applied on zirconia for CAD/CAM processing by the layering technique and the heat pressing technique, and the effects of the method and material type on the debonding/ crack initiation and 3-point flexural strengths of 
bilayered zirconia core and veneering ceramic composites were investigated. The null hypothesis proposed in this research is that the 3-point flexural strength of bilayered zirconia core and veneering ceramic composites depends only on the strength of the veneer material itself, regardless of the debonding/crack initiation strength of composites.

\section{MATERIALS AND METHODS}

\section{Experimental materials}

3Y-TZP Zirconia block (Zirtooth, Hass, Gangneung, Korea) for CAD/CAM processing was used as core material. As veneering materials, Cerabien ZR (Noritake, Nagoya, Japan) and Lava Ceram (3M ESPE, Seefeld, Germany) were used for the layering technique, and IPS e.max ZirPress (Ivoclar vivadent, Schaan, Liechtenstein) and Amber LiSi-POZ (Hass) were used for the heat pressing technique (Table 1).

\section{Measurement of the biaxial flexural strength of veneering ceramics}

The powder of each type of ceramic used for the layering technique was mixed with the solution manufactured for each ceramic to create a viscous mixture. Then, specimens were created by filling a $1.8 \mathrm{~mm}$-thick metal mold with an inner diameter of $17 \mathrm{~mm}$ with the mixture and using tissue to absorb the moisture. After this, specimens were fired under the firing conditions recommended by the manufacturing company as shown in Table 2 . When creating the specimen for heat pressing technique, a self-polymerizing pattern resin (GC, Tokyo, Japan) was used. To create disc-shaped specimens, powder and liquid were mixed in proportion of $2: 1$ and poured into a $1.2 \mathrm{~mm}$-thick metal mold with an inner diameter of 13 $\mathrm{mm}$. After this, pressure was applied with a glass plate after interposing a polyethylene sheet to remove excess resin. After preparing 10 patterns per each material, they were buried and heat pressed according to the conditions recommended by the manufacturer as shown in Table 2. Then, after removing the investing material from the surface of each specimen, specimens were sequentially polished with SiC sandpaper starting from \#400 until \#2000. Then, polishing process was finished with a $1 \mu \mathrm{m}$-diamond paste (Beuhler, Lake Bluff, IL, USA) to remove micro defects of the surface.

To measure the strength of disc-shaped specimens, a biaxial flexural test was performed as required by ISO/ CD 6872.2:2005 as shown in Fig. 1a. After mounting a load device for biaxial flexural test on the material testing machine (4201, Instron, Norwood, MA, USA), a compressive force was applied at crosshead speed $(0.5 \mathrm{~mm} / \mathrm{min})$ to record the load at the moment when fracture occurred. The biaxial flexural strength $(\sigma)$ was calculated using Eq. (1)-(3).

$$
\begin{aligned}
& \mathrm{S}=-0.2387\left[P(X-Y) / d^{2}\right] \\
& \mathrm{X}=(1+v) \ln \left(\mathrm{r}_{2} / \mathrm{r}_{3}\right)^{2}+[(1-v) / 2]\left(\mathrm{r}_{2} / \mathrm{r}_{3}\right)^{2} \\
& \mathrm{X}=(1+v)\left[1+\ln \left(\mathrm{r}_{1} / \mathrm{r}_{3}\right)^{2}\right]+(1-v)\left(\mathrm{r}_{1} / \mathrm{r}_{3}\right)^{2}
\end{aligned}
$$

Here, $\mathrm{S}$ is the maximum biaxial flexural strength (MPa), $P$ is the specimen's fracture load $(\mathrm{N}), v$ is Poisson's ratio (0.25), $\mathrm{r}_{1}$ is the radius of the supporting circle $(\mathrm{mm}), \mathrm{r}_{2}$ is the circumferential radius of the load part $(\mathrm{mm})$, and $r_{3}$

Table 1 Veneering materials used in the study

\begin{tabular}{lcllc}
\hline Veneering material & Code & \multicolumn{1}{c}{ Manufacturer } & Ceramic type & CTE* $\left(10^{-6} / \mathrm{K}\right)$ \\
\hline Cerabien ZR & CZ & Noritake, Nagoya, Japan & Feldspar & 9.1 \\
Lava Ceram & LC & 3M ESPE, Seefeld, Germany & Fluorapatite & 10.0 \\
IPS e.max ZirPress & IZ & Ivoclar/Vivadent, Schaan, Liechtenstein & Fluorapatite & 9.8 \\
Amber LiSi-POZ & AL & Hass, Kangreung, Korea & Lithium disilicate & 10.0 \\
\hline
\end{tabular}

\begin{tabular}{|c|c|c|c|c|c|c|c|c|}
\hline \multirow{2}{*}{ Materials } & \multirow{2}{*}{ Code } & \multicolumn{2}{|c|}{ Pre-Drying } & \multirow{2}{*}{$\begin{array}{c}\text { TRI } \\
\left({ }^{\circ} \mathrm{C} / \mathrm{min}\right)\end{array}$} & \multirow{2}{*}{$\begin{array}{l}\mathrm{FT} \\
\left({ }^{\circ} \mathrm{C}\right)\end{array}$} & \multirow{2}{*}{$\mathrm{V} 1$} & \multirow{2}{*}{$\mathrm{V} 2$} & \multirow{2}{*}{$\begin{array}{c}\mathrm{HT} \\
\text { (min) }\end{array}$} \\
\hline & & $\mathrm{ST}\left({ }^{\circ} \mathrm{C}\right)$ & DT (min) & & & & & \\
\hline Cerabian ZR & $\mathrm{CZ}$ & 450 & 8 & 45 & 930 & 450 & 930 & 1 \\
\hline Lava ceram & $\mathrm{LC}$ & 500 & 7 & 45 & 920 & 500 & 910 & 1 \\
\hline IPS e.max ZirPress & $\mathrm{IZ}$ & 700 & 1 & 60 & 910 & 700 & 910 & 15 \\
\hline Amber LiSi-POZ & $\mathrm{AL}$ & 650 & 1 & 60 & 925 & 650 & 925 & 20 \\
\hline
\end{tabular}

*CTE based on manufacturer scientific data

Table 2 Firing schedules of veneering ceramic materials

ST: starting temperature; DT: drying time; FT: final temperature; TRI: temperature rate increase; V1: vacuum on; V2: vacuum off; HT: holding time 


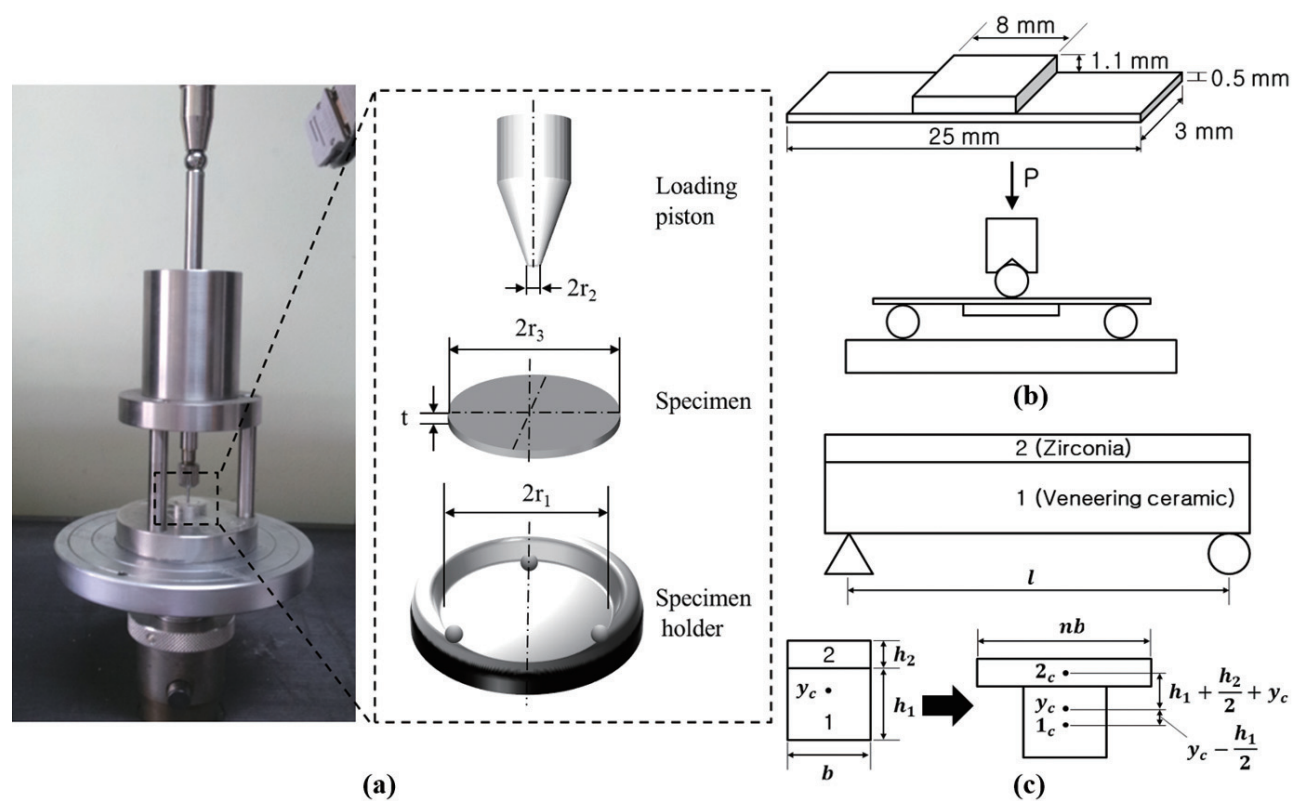

Fig. 1 Schematic image of (a) biaxial flexural test for veneering ceramics, (b) flexural test for the measurement of debonding/crack initiation between veneering ceramic and zirconia according to ISO 9693, and (c) 3-point flexural test of the bilayered zirconia core and veneering ceramic composites and transformation of area with same elastic modulus of composite beam.

is the specimen's radius $(\mathrm{mm})$.

\section{Measurement of the debonding/crack initiation strength between veneering ceramic and zirconia}

To prepare 40 specimens for the measurement of debonding/crack initiation strength, a Zirtooth disc block (Hass) was cut into $3 \mathrm{~mm}$ width, $0.5 \mathrm{~mm}$ thick and 25 $\mathrm{mm}$ long, and temperature was raised at a heating rate of $8.3^{\circ} \mathrm{C} / \mathrm{min}$ and maintained during $2 \mathrm{~h}$ at $1,450^{\circ} \mathrm{C}$.

The test to measure the debonding/crack initiation strength of bilayered zirconia core and veneering ceramic composites was performed in accordance with ISO9693. $50 \mu \mathrm{m}$-alumina powder (Cobra aluminum oxide, 1594-1205, Renfert, Hilzingen, Germany) was sprayed at $2 \mathrm{~atm}$ of pressure on the $8 \mathrm{~mm}$-wide part in the center of the zirconia specimen and heat treated for $5 \mathrm{~min}$ at $1,000^{\circ} \mathrm{C}$ to restore the phase transition layer. In the case of two kinds of the ceramics for applying the layering technique, the powder of each type of ceramic was mixed with the solution manufactured for each ceramic to create a viscous mixture. Then, mixture were filled in a Teflon mold patterned with $0.3 \mathrm{~mm}$-thick and $3 \mathrm{~mm}$ width and $8 \mathrm{~mm}$ long, and then with the mixture and using tissue to absorb the moisture. After this, specimens were fired under the firing conditions recommended by the manufacturing company. The mold was filled with the mixture using vibration after locating the mold on the zirconia specimen, after which moisture was absorbed using tissue. Then, the specimen was molded so that it would be $0.3 \mathrm{~mm}$ thick and fired for the first time. After that, the specimen was molded and fired for the second time so that it would become about $1.1 \mathrm{~mm}$ thick. Finally, it was molded and fired for the third time so that the thickness of veneer ceramics would be of (1.1 \pm 0.1$) \mathrm{mm}$ as shown in Fig. 1b. In the case of two kinds of the ceramics for applying heat pressing technique, pattern resin was applied to the $8 \mathrm{~mm}$-wide part of the zirconia specimen's center to create a $1.1 \mathrm{~mm}$ thick layer. After this, it was buried and casted according with the conditions recommended by the manufacturer, and then molded by heat pressing. After this, it was blasted with glass bead at $2 \mathrm{~atm}$ to remove the investing material from the specimen's surface.

The load which the fracture occurred at the bonding interface was measured using the material testing machine (4201, Instron) at a loading rate of $1.5 \pm 0.5 \mathrm{~mm} /$ min after installing the test jig with a span distance of $20 \mathrm{~mm}$. The debonding/crack initiation strength $(\sigma)$ between zirconia and veneer ceramic was calculated using the following equation.

Debonding/crack initiation Strength $(\sigma)=k \cdot F_{\text {failure }}$

Here, $k$ which is the coefficient determined by zirconia's Young's modulus $\left(\mathrm{E}_{\mathrm{M}}\right)$ and the thickness of the zirconia specimen $\left(d_{M}\right)$ in accordance with ISO9693. In this research, zirconia's Young's modulus was set to be 210 $\mathrm{GPa}^{12)}$.

Measurement of the 3-point flexural strength of the bilayered zirconia core and veneering ceramic composites

After preparing 40 Zirtooth plate specimens of $3 \mathrm{~mm}$ (width) $\times 0.5 \mathrm{~mm}$ (thickness) $\times 25 \mathrm{~mm}$ (length), the bonding 
part was sprayed with $50 \mu \mathrm{m}$ alumina powder at $2 \mathrm{~atm}$ of pressure and heated during $5 \mathrm{~min}$ at $1,000^{\circ} \mathrm{C}$ after rising the temperature with a heating rate of $8.3^{\circ} \mathrm{C} / \mathrm{min}$ to restore the phase transition layer. Then, according with the conditions recommended by each manufacturer, the layer of veneering ceramic was formed on the zirconia surface so that it would become $1.1 \mathrm{~mm}$ thick to make a bilayered zirconia core and veneering ceramic composites. The load which chipping occurred at the veneering ceramic was measured by the material testing machine (4201, Instron) at a loading rate of $0.5 \mathrm{~mm} / \mathrm{min}$ after installing the jig with a span distance of $20 \mathrm{~mm}$.

The 3-point flexural strength was calculated by the composite beam theory. As shown in Fig. 1c, the composite beam composed by zirconia (material 1) and veneered ceramic (material 2), which have different young's moduli, was converted into one material with the same young's modulus, and then the veneered ceramic's 3-point flexural strength $\left(\sigma_{\mathrm{p}}\right)$ was calculated using following Eq. (5).

$$
\sigma_{p}=\frac{M y_{c}}{I_{t}}
$$

Here, $M$ is the bending moment, $y_{c}$ is the distance from the specimen's underside until the sectional center, and $I_{t}$ is the secondary moment of the neutral axis of the converted section.

The distance from the specimen's underside until the sectional center $\left(y_{c}\right)$ and the secondary moment of the section $\left(I_{t}\right)$ can be expressed as Eqs. (6) and (7).

$$
\begin{aligned}
y_{c} & =\frac{b h_{1} \times \frac{b h_{1}}{2}+b n h_{2} \times\left(\frac{h_{1}+h_{2}}{2}\right)}{b h_{1}+b n h_{2}} \\
I_{t} & =I_{1}+n l_{2}=\frac{1}{12} b h_{1}{ }^{3}+b h_{1}\left(\mathrm{y}-\frac{h_{1}}{2}\right)^{2}+\frac{1}{12} b h_{2}{ }^{3} \\
& +b h_{2}\left(h_{1}+\frac{h_{2}}{2}-y_{c}\right)^{2}
\end{aligned}
$$

Here, $b$ is the specimen's width, and $n$ is the young's modulus ratio of materials 1 and 2 .

\section{Observation of microstructure}

After polishing the surface, the porcelain was etched using $1 \% \mathrm{HF}$ aqueous solution during $1 \mathrm{~min}$. Also, the ceramic containing fluorapatite crystals was etched using $3 \% \mathrm{HF}$ aqueous solution during $10 \mathrm{~s}$, and the lithium-disilicate crystal reinforced ceramic was etched using 9\% HF aqueous solution during $30 \mathrm{~s}$. Then, the surface of each specimen was observed using a highresolution field emission scanning electron microscope (HR FE-SEM in KBSI in Jeonju, S800, Hitachi, Tokyo, Japan) after platinum coating.

\section{Statistical analysis}

After verifying the statistical significance of the measured values using one-way ANOVA, the difference between groups was compared by the Tukey HSD test

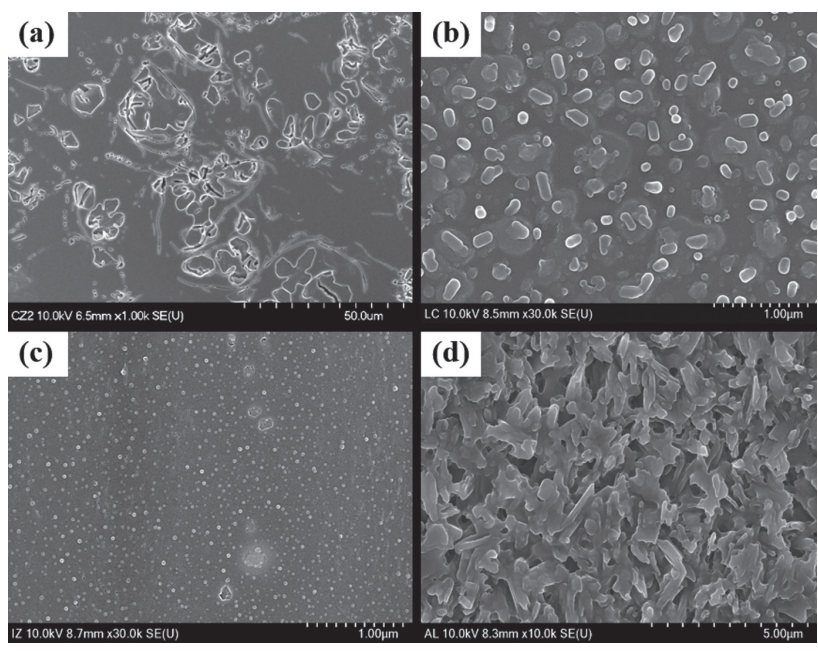

Fig. 2 HR FE-SEM images of the microstructure for 4 types of ceramics veneered on zirconia core.

(a) CZ, (b) LC, (c) IZ, (d) AL.

as post-test method. A significance level ( $p$-value) of less than 0.05 was considered as statistical significance.

\section{RESULTS}

Figure 2 shows the morphologies of the microstructure for the 4 kinds of ceramics veneered on zirconia core. The leucite crystalline phases were dispersed in the CZgroup (Fig. 2a) for layering technique. The fluorapatite crystalline phases were dispersed in the LC-group (Fig. 2b) for layering technique and in the IZ-group (Fig. 2c) for heat pressing technique. The crystalline phases were finer in the IZ-group (Fig. 2c) than in the LC-group (Fig. $2 b)$. The needle-shaped lithium-disilicate crystalline phases were dispersed in AL-group (Fig. 2d) for heat pressing technique.

Figure 3 shows the average biaxial flexural strength for the 4 kinds of veneering ceramic, the debonding/ crack initiation strength measured according to ISO 9693 between zirconia and the veneered ceramic, and the strength measured at the moment when chipping occurred in the veneer during the 3-point flexural test of the bilayered zirconia core and veneering ceramic composites. The value of biaxial flexural strength was the lowest in the LC-group $(77.9 \pm 14.3 \mathrm{MPa})$ and the highest in the AL-group (344.8 $\pm 26.9 \mathrm{MPa})$. The AL-group was different from other groups in terms of statistical significance $(p<0.05)$. The lowest value of the debonding/crack initiation strength was found in the CZgroup $(28.5 \pm 3.4 \mathrm{MPa})$, and the highest value was found in the AL-group (41.3 $\pm 5.1 \mathrm{MPa})$. There was a difference in terms of statistical significance between the Algroup and the CZ-group $(p<0.05)$. The value of 3 -point flexural strength for the bilayered zirconia core and veneering ceramic composites was the lowest in the CZgroup (53.6 $\pm 3.8 \mathrm{MPa})$ and the highest in the AL-group $(152.7 \pm 14.2 \mathrm{MPa})$. A difference in terms of statistical 


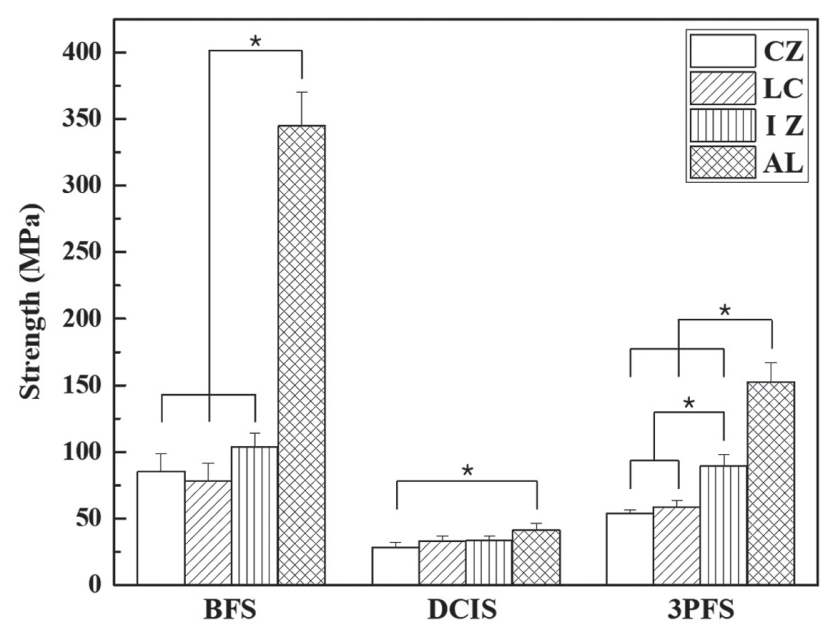

Fig. 3 Graph for Biaxial flexural strength of veneering ceramics (BFS), debonding/crack initiation strengths of ceramics veneered on zirconia core (DCIS), and 3-point flexural strengths of bilayered zirconia core and veneering ceramic composites (3PFS).

* indicates the statistically significant difference between groups.

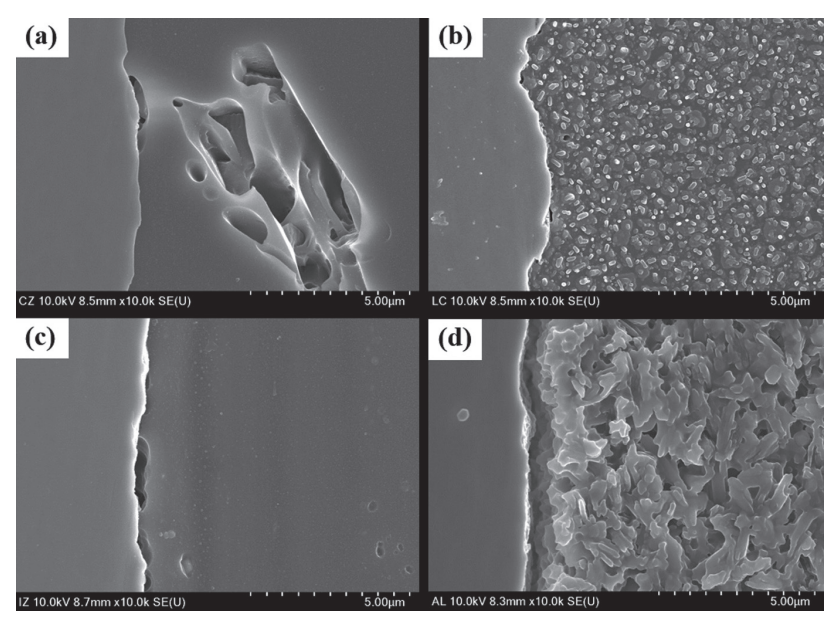

Fig. 4 HR FE-SEM images of interfaces between zirconia core and veneering ceramics.

(a) CZ, (b) LC, (c) IZ, (d) AL.

significance was found between all groups except the CZ and LC-groups $(p<0.05)$.

Figure 4 shows the HR FE-SEM images of the bonding interface between veneering ceramics and core. Some defects and microgaps were observed in the bonding interface of all test groups.

Figure 5 shows HR FE-SEM images of the zirconia surfaces after measuring the bonding strength between cores and veneering ceramics. It was observed that the reactive layer covered the zirconia surface in the bonding interface of all test groups. Cohesive fractures were dominantly found in the destructed surface of $\mathrm{CZ}$

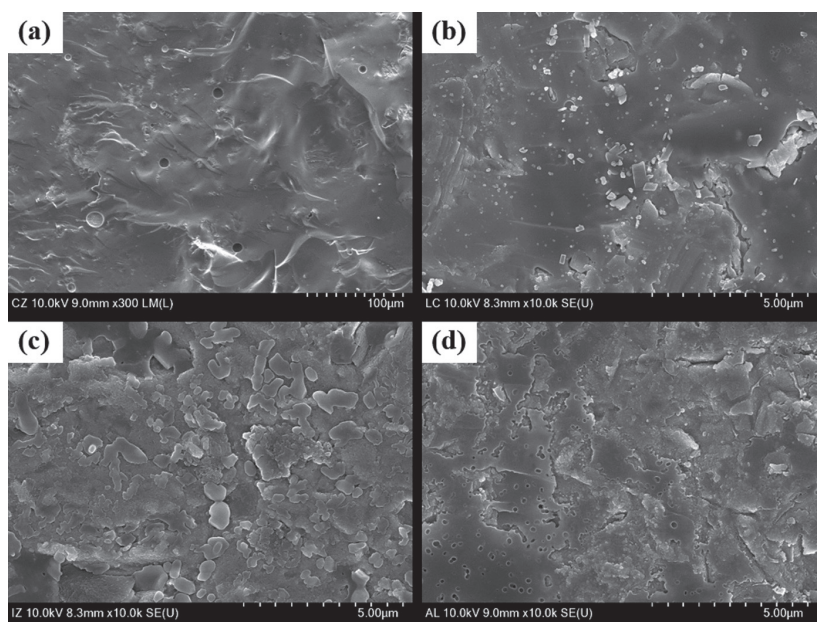

Fig. 5 HR FE-SEM images of fractured or veneerdelaminated zirconia surfaces.

(a) CZ, (b) LC, (c) IZ, (d) AL.

and LC-groups applying the layering technique, and mixed fractures which the zirconia surface was partially exposed were dominantly found in IZ and AL-groups applying heat pressing technique.

\section{DISCUSSION}

In this research, results of tests for the bilayered zirconia core and veneering ceramic composites revealed that the 3-point flexural strength of veneering ceramic increased with increasing debonding/crack initiation strength, which rejected partially the null hypothesis of this research.

Glass-ceramics or feldspathic porcelains have been veneered on zirconia to manufacture the bilayered zirconia all-ceramic crowns with the excellent mechanical properties and improved esthetics because zirconia ceramics have lower translucency by their high crystalline content ${ }^{13,14)}$. Even though bilayered zirconiabased restorations use the zirconia cores with high strength, it was lately reported that the estimated 5-year survival rates for zirconia-ceramic implant-supported fixed dental prostheses (FDPs) of 93\% was lower than it for metal-ceramic implant-supported FDPs of $98.7 \%$, but the complication rates which the repair were required by ceramic fracture and chipping were $2.5 \%$ for zirconiaceramic implant-supported FDPs and $4.7 \%$ for metalceramic implant-supported FDPs respectively ${ }^{15)}$. In the latest clinical review, it was confirmed that five-year survival estimates of implants supporting partial and full-arch all-ceramic implant-supported fixed dental prostheses (P-FDPs and FA-FDPs) were $98.5 \%$ and $99.4 \%$ respectively, but the estimated 5-year complication rates by chipping of the veneering ceramic were $22.8 \%$ $(\mathrm{P}-\mathrm{FDPs})$ and $34.8 \%(\text { FA-FDPs })^{16}$. Fortunately, most clinical studies reported that most of chippings were considered for very small fractures that could be simply 
polished or repaired simply using resin composites in the oral cavity, and a few of chippings were considered large fractures that require removal ${ }^{17)}$. But, the chipping of the veneering ceramic is still contemplated very inconvenient complication in the dental clinic ${ }^{17}$. Thus, many researchers have been trying to solve the problem of chipping for prolong usable period of restorations.

Actually, the chipping and delamination of veneering ceramics are affected by various factors such as mechanical properties of veneering ceramics, residual stress caused by thermal incompatibility, bonding between the veneer ceramic and zirconia core and pores and micro gaps in the bonding interface and inside the sintered body ${ }^{18-20}$. Both the debonding/crack initiation and the 3-point flexural strengths were higher in case of applying heat pressing technique then in case of applying the layering technique in this study. The reason for higher debonding/crack initiation strength when using heat pressing technique might be because the manufacturing process of the heat pressing technique is more accurate and generates less inner bubbles than the conventional layering technique, as explained by Dong et. al. ${ }^{11)}$ and Gorman et. al. ${ }^{21)}$. Many previous studies reported that zirconia specimens veneered using a heat pressing technique had higher mechanical properties than them of layering technique, since the heat pressing technique reduces the exposure of zirconia to moisture by fewer firing step and provide higher density by pressure as well as less micro gap formation and defects caused by deformation and cooling stress differences than the layering technique ${ }^{22-24)}$. Also, the heat pressing technique has some clinical benefits like accelerating the working speed and decreasing the technique sensitivity ${ }^{25)}$. These advantages of the heat-pressing technique can decrease the chipping and delamination veneering ceramics from zirconia core. In previous clinical study, it was reported that the prosthesis using heat pressing technique (vs. traditional method) had a lower fracture rate 2 years later than the layering technique in both zirconia and metal ceramics ${ }^{26)}$.

Delamination and chipping of veneering ceramic from a bilayered all-ceramic restoration can be occurred by the residual thermal stresses at the core-veneer interface resulted from a considerable mismatch of the coefficient of thermal expansion (CTE) between zirconia core and veneering ceramic ${ }^{17,27)}$. Veneering ceramics with slightly lower CTE than zirconia core have been recommend to induce residual compressive stress in veneering layer since the chipping of veneering layer can be more easily occurred by the combination of the tensile stress generated during mastication when the residual stresses are the tensile type in veneering layer $^{27-29)}$. However, this also generate the tensile stress in zirconia core, which has a negative impact on the zirconia core ${ }^{24)}$. Thus, the CTE difference between $-0.61 \times 10^{-6}$ and $+1.02 \times 10^{-6} / \mathrm{K}$ was recommend to prevent the occurrence of high residual stresses ${ }^{30}$. As shown in Table 1, the CTEs of veneering ceramics used in this study have lower CTE than zirconia $\left(10.7 \times 10^{-6} / \mathrm{K}\right.$ based on manufacturer scientific data), which means that all veneering layers are under residual compressive stress. Also, the CTE differences between veneering ceramics and zirconia are in above range except CZ-group. Thus, it is considered that CTE mismatch not affected the mechanical properties much, but this might result in the lowest the debonding/crack initiation strength and 3-point flexural strength of CZ-group slightly in this study.

This being so, it is thought that higher 3-point flexural strengths of IZ and AL groups applying heat pressing technique than them of $\mathrm{CZ}$ and LC gourps applying layering technique resulted from the tempering residual stress which is the different kind of residual thermal stress being developed thermal gradient in a bilayered all-ceramic restoration during cooling from the temperature above the glass transition point ${ }^{31-33)}$. The distribution and magnitude of residual stress formed in a bilayered all-ceramic restoration are usually affected by the thermal expansion mismatch associated with difference of CTE between the veneering and framework materials and the tempering residual stress associated with cooling rate as well as the relative thickness of the veneering and framework materials ${ }^{33)}$. In previous studies conducted by Asaoka, it was confirmed that the magnitude of the transient and residual stresses in porcelain of metal-porcelain strip increased with cooling rate $^{31,32)}$. Also, Swain reported that compressive stress is distributed at the surface within the external $16 \%$ of thickness of porcelain and compensating tensile stress develop internally when analyzed the distribution of the combined thermal mismatch and tempering residual stress for the bilayered model made of $1 \mathrm{~mm}$ zirconia framework and $3 \mathrm{~mm}$ thickness of veneering porcelain cooled at $50^{\circ} \mathrm{C} / \mathrm{s}^{33)}$. This distribution of residual stress makes cracks harder to generate initially due to the surface compressive stress, but once cracks start developing, crack extension can be promoted by internal tensile stress and chipping of veneering ceramic can easily occurred ${ }^{33)}$. Thus, slower cooling rate for minimal thermal gradient in materials is beneficial to minimize the magnitude of tempering residual stress in veneering ceramic bilayered on zirconia core with the low thermal diffusivity ${ }^{33)}$. For that reason, it is considered that groups applying heat pressing technique had higher 3 -point flexural strengths than them of groups applying layering technique in this study since heat pressing technique potentially can reduce the magnitude of tempering residual stress by relatively lower thermal gradient in veneering ceramic bilayered on zirconia core than layering technique.

Also, in case of the fluorapatite-crystal reinforced glass ceramic, the 3-point flexural strength of IZ-group applying the heat pressing technique was significantly higher than that of LC-group applying layering technique, depending on the method of applying the veneering ceramics. The reason of this is that, when using the heat pressing technique, molding can be performed by applying pressure only once after softening the ingot. However, when using layering technique, inner pores were generated and fluorapatite crystals were coarsened 
during the repeated layering process, which resulted in the decrease of the 3-point flexural strengths. The 3-point flexural strengths of the AL-group was significantly higher than in other groups, which was resulted from the intrinsic superior fracture resistance of the lithiumdisilicate crystal reinforced glass-ceramic.

Chipping and delamination of veneering ceramic are fracture modes occurring in the veneer ceramic and at the bonding interface respectively ${ }^{34}$. In previous studies, various fracture modes such as cohesive, adhesive and mixed fractures were identified by different test methods ${ }^{35-37}$. However, the bilayered zirconia all-ceramic crowns showed higher failures by cohesive fracture than adhesive fracture in clinical study, which could resulted from the intrinsic low mechanical properties of veneering ceramics and defects within the veneering ceramic formed during the layering process ${ }^{38}$. Also, the bonding strength between zirconia core and veneering ceramic is crucial since the delamination can be occurred by adhesive fracture resulted from the weak bonding strength. When applying layering technique and heat pressing technique, cohesive failure and mixed fractures were respectively observed on the destructed surface of zirconia's core at the bonding interface in this study. The reason that the groups of heat pressing technique showed higher chipping strength and mixed fractures is because the bonding was occurred between zirconia and veneers by chemical reaction due to longer holding time at high temperature than that of layering technique ${ }^{39}$.

Considering all results of this study, it is useful to use the heat pressing technique and veneering material with superior mechanical properties to prevent the chipping and delamination of veneering ceramic of the bilayered zirconia all-ceramic crowns.

\section{CONCLUSION}

Veneering ceramics were applied on zirconia by the layering technique and the heat pressing technique, and then the effects of the veneering materials and methods on their mechanical properties were investigated in this study. The biaxial and triaxial flexural strengths and debonding/crack initiation strength were higher when applying heat pressing technique then when applying layering technique. The mechanical properties of ALgroup were the highest in comparison to other groups, which showed statistically significant difference. It was identified that the debonding/crack initiation strength and triaxial flexural strength of the zirconia and veneering ceramic composites are affected by the magnitude of residual stress which resulted from veneering method as well as the intrinsic strength of veneering ceramic material. Thus, the choice of veneering method which can develop optimal distribution of residual stress in bilayered composite using veneering ceramic with high strength are crucial to prevent the chipping of veneering ceramic in bilayered zirconia core and veneering ceramic composites.

\section{ACKNOWLEDGMENTS}

This paper was supported by Fund of Biomedical Research Institute, Chonbuk National University Hospital. YongSeok Jang and Chung-Ha Lim contributed equally to this study and should be considered co-first authors. The authors declare that they have no conflicts of interest.

\section{REFERENCES}

1) Kang D, Park J, Bae T. Evaluation of crack propagation aspects of dental ceramic materials under static loading conditions. J Kor ReS Soc Der Mater 1999; 26: 75-82.

2) Yamamoto M. Metal-ceramics: principle and methods of Makoto Yamamoto: Quintessence Publishing Company; 1985.

3) Piddock V, Qualtrough A. Dental ceramics -An update. J Dent 1990; 18: 227-235.

4) Kosmač T, Oblak Č, Marion L. The effects of dental grinding and sandblasting on ageing and fatigue behavior of dental zirconia (Y-TZP) ceramics. J Eur Ceram Soc 2008; 28: 10851090.

5) Denry I, Kelly JR. State of the art of zirconia for dental applications. Dent Mater 2008; 24: 299-307.

6) Ban S. Reliability and properties of core materials for allceramic dental restorations. J Dent Sci Rev 2008; 44: 3-21.

7) Kosmač T, Oblak C, Jevnikar P, Funduk N, Marion L. The effect of surface grinding and sandblasting on flexural strength and reliability of Y-TZP zirconia ceramic. Dent Mater 1999; 15: 426-433.

8) Luthardt R, Holzhüter M, Sandkuhl O, Herold V, Schnapp J, Kuhlisch E, et al. Reliability and properties of ground Y-TZPzirconia ceramics. J Dent Res 2002; 81: 487-491.

9) Kelly J, Tesk J, Sorensen J. Failure of all-ceramic fixed partial dentures in vitro and in vivo: analysis and modeling. J Dent Res1995; 74: 1253-1258.

10) Larsson C, von Steyern Vult P, Sunzel B, Nilner K. Allceramic two-to five-unit implant-supported reconstructions. A randomized, prospective clinical trial. Swed Dent J 2006; 30: $45-53$.

11) Dong J, Luthy H, Wohlwend A, Schärer P. Heat-pressed ceramics: technology and strength. Int J Prosthodont 1992; 5: 9-16.

12) Guess PC, Schultheis S, Bonfante EA, Coelho PG, Ferencz JL, Silva NR. All-ceramic systems: laboratory and clinical performance. Dent Clin North Am 2011; 55: 333-352.

13) Kurtulmus-Yilmaz S, Ulusoy M. Comparison of the translucency of shaded zirconia all-ceramic systems. J Adv Prosthodont 2014; 6: 415-422.

14) Zhang Y. Making yttria-stabilized tetragonal zirconia translucent. Dent Mater 2014; 30: 1195-1203.

15) Sailer I, Strasding M, Valente NA, Zwahlen M, Liu S, Pjetursson BE. A systematic review of the survival and complication rates of zirconia-ceramic and metal-ceramic multiple-unit fixed dental prostheses. Clin Oral Implants Res 2018; 29: 184-198.

16) Pieralli S, Kohal RJ, Rabel K, von Stein-Lausnitz M, Vach K, Spies BC. Clinical outcomes of partial and full-arch all-ceramic implant-supported fixed dental prostheses. A systematic review and meta-analysis. Clin Oral Implants Res 2018; 29: 224-236.

17) de Lima E, Meira JBC, Özcan M, Cesar PF. Chipping of veneering ceramics in zirconium dioxide fixed dental prosthesis. Curr Oral Health Rep 2015; 2: 169-173.

18) De Jager N, Pallav P, Feilzer AJ. The influence of design parameters on the FEA-determined stress distribution in CAD-CAM produced all-ceramic dental crowns. Dent Mater 2005; 21: 242-251. 
19) Zhao K, Pan Y, Guess PC, Zhang XP, Swain MV. Influence of veneer application on fracture behavior of lithium-disilicatebased ceramic crowns. Dent Mater 2012; 28: 653-660.

20) Wang G, Zhang S, Bian C, Kong H. Fracture mechanics analyses of ceramic/veneer interface under mixed-mode loading. J Mech Behav Biomed Mater 2014; 39: 119-128.

21) Gorman C, McDevitt W, Hill R. Comparison of two heatpressed all-ceramic dental materials. Dent Mater 2000; 16: 389-395.

22) Zaher AM, Hochstedler J, Rueggeberg FA, Kee EL. Shear bond strength of zirconia-based ceramics veneered with 2 different techniques. J Prosthet Dent 2017; 118: 221-227.

23) Ishibe M, Raigrodski AJ, Flinn BD, Chung KH, Spiekerman C, Winter RR. Shear bond strengths of pressed and layered veneering ceramics to high-noble alloy and zirconia cores. J Prosthet Dent 2011; 106: 29-37.

24) Aboushelib MN, de Kler M, van der Zel JM, Feilzer AJ. Effect of veneering method on the fracture and bond strength of bilayered zirconia restorations. Int J Prosthodont 2008; 21: 237-240.

25) Oh JW, Song KY, Ahn SG, Park JM, Lee MH, Seo JM. Effects of core characters and veneering technique on biaxial flexural strength in porcelain fused to metal and porcelain veneered zirconia. J Adv Prosthodont 2015; 7: 349-357.

26) Christensen G. PFM vs. zirconia restorations - how are they comparing clinically. Clin Rep 2008; 1: 1-2.

27) Sakaguchi RL, Powers JM. Craig's restorative dental materials-e-book: Elsevier Health Sciences; 2012.

28) Tholey MJ, Swain MV, Thiel N. Thermal gradients and residual stresses in veneered Y-TZP frameworks. Dent Mater 2011; 27: 1102-1110.

29) Fischer J, Stawarczyk B, Tomic M, Strub JR, Haemmerle CH. Effect of thermal misfit between different veneering ceramics and zirconia frameworks on in vitro fracture load of single crowns. Dent Mater J 2007; 26: 766-772.
30) DeHoff PH, Barrett AA, Lee RB, Anusavice KJ. Thermal compatibility of dental ceramic systems using cylindrical and spherical geometries. Dent Mater 2008; 24: 744-752.

31) Asaoka K. Transient and residual stress in porcelain/ alloy strip for dental use as affected by tempering. JSME international journal Ser 1, Solid mechanics, strength of materials 1991; 34: 156-162.

32) Asaoka K, Tesk J. Visco-elastic deformation of dental porcelain and porcelain-metal compatibility. Dent Mater 1991; 7: 30-35.

33) Swain M. Unstable cracking (chipping) of veneering porcelain on all-ceramic dental crowns and fixed partial dentures. Acta Biomater 2009; 5: 1668-1677.

34) Aboushelib MN, Kleverlaan CJ, Feilzer AJ. Microtensile bond strength of different components of core veneered allceramic restorations: Part II: Zirconia veneering ceramics. Dent Mater 2006; 22: 857-863.

35) Çömlekoğlu ME, Dündar M, Özcan M, Güngör MA, Gökçe B, Artunç C. Evaluation of bond strength of various margin ceramics to a zirconia ceramic. J Dent 2008; 36: 822-827.

36) Cesar PF, Soki FN, Yoshimura HN, Gonzaga CC, Styopkin $\mathrm{V}$. Influence of leucite content on slow crack growth of dental porcelains. Dent Mater 2008; 24: 1114-1122.

37) Choi JE, Waddell JN, Torr B, Swain MV. Pressed ceramics onto zirconia. Part 1: Comparison of crystalline phases present, adhesion to a zirconia system and flexural strength. Dent Mater 2011; 27: 1204-1212.

38) Al-Amleh B, Waddell JN, Lyons K, Swain MV. Influence of veneering porcelain thickness and cooling rate on residual stresses in zirconia molar crowns. Dent Mater 2014; 30: 271280.

39) Mainjot AK, Douillard T, Gremillard L, Sadoun MJ, Chevalier J. 3D-Characterization of the veneer-zirconia interface using FIB nano-tomography. Dent Mater 2013; 29: 157-165. 